\title{
Age is a predictor of significant endoscopic findings in dyspepsia patients in South Africa
}

\author{
S Cheddie, ${ }^{1}$ (D) CG Manneh, ${ }^{1}$ (D) BM Owczarek, ${ }^{1}$ (D) Y Moodley ${ }^{2}$ (D) \\ ${ }^{1}$ Department of Surgery, Madadeni Hospital, University of KwaZulu-Natal, South Africa \\ ${ }^{2}$ Faculty of Health and Environmental Sciences, Central University of Technology, South Africa
}

Corresponding author, email: scheddie@gmail.com

Background: Dyspepsia is the commonest indication for endoscopy. Current American guidelines recommend that all dyspepsia patients $\geq 60$ years undergo endoscopy to exclude significant pathology. The use of this age cut-off has never been analysed in South Africa. We aimed to compare different age cut-offs as predictors of significant endoscopic findings in patients with a primary diagnosis of dyspepsia.

Methods: A retrospective chart review of 1000 consecutive endoscopies done at Madadeni Provincial Hospital, KwaZuluNatal, from 2014 to 2016 was performed. All patients with dyspepsia were identified and divided into age $\geq 60$ and $<60$ cohorts and $<45$ and $\geq 45$ cohorts. Demographic data, significant endoscopic findings (tumour, ulcer, and stricture) and non-significant findings (gastritis, hiatus hernia, candidiasis, and oesophagitis, normal) were recorded.

Results: 584 patients (58.4\%) presented with dyspepsia, with a median age of 49 years (interquartile range: $14-87)$. There were 142 males $(24.4 \%)$ and 442 females $(75.6 \%) .432(74 \%)$ patients in the age $<60$ cohort and $152(26 \%)$ in the age $\geq 60$ cohort. There were $238(41 \%)$ patients in the $<45$ cohort and $346(59 \%)$ patients in the $\geq 45$ cohort. In the age $<60$ cohort, $6.7 \%$ of patients had significant findings, compared to $17.1 \%$ of patients in the age $\geq 60$ cohort $(p$-value $<0.001)$. In the age $\geq 60$ cohort, the positive predictive value (PPV) of endoscopy was $17 \%$, negative predictive value (NPV) (93\%) and odds ratio (OR) (2.87) $p<0.001$. In the age $<45$ cohort, $4.2 \%$ of patients had significant findings, compared to $13 \%$ of patients in the $\geq 45$ cohort ( $p$-value $<0.001$ ). In the age $\geq 45$ cohort, the PPV was $13 \%$, NPV (96\%) and OR (3.41) $p<0.001$. There is no overall difference in significant endoscopic findings between the age $\geq 45$ and age $\geq 60$ groups $(p=0.230)$.

Conclusion: Age is a predictor of significant endoscopic findings in dyspepsia patients. Patients $\geq 60$ years with dyspepsia symptoms should undergo a routine endoscopy in the absence of alarm symptoms. The current ACG guidelines can be applied in the South African context.

Keywords: dyspepsia, age cut-off, endoscopy, odds ratio

\section{Introduction}

Dyspepsia is predominant epigastric pain lasting at least 1 month. This can be associated with any other upper gastrointestinal symptom, such as epigastric fullness, nausea, vomiting or heartburn, provided epigastric pain is the patient's primary concern. ${ }^{1}$

The prevalence of dyspepsia in the South African population is unknown, while the prevalence of dyspepsia in north-east Africa is estimated at $26-68.6 \% .^{2}$ It is the most frequent indication for upper gastrointestinal endoscopy and places a burden on healthcare resources where there is a lack of well-functioning equipment and skilled endoscopists. ${ }^{3}$ Adherence to clinical guidelines is therefore essential to ensure that dyspepsia patients are appropriately investigated in a cost-efficient manner.

The current American College of Gastroenterology (ACG) guidelines suggest that dyspepsia patients over the age 60 undergo routine endoscopy. ${ }^{1}$ The age criteria has increased from 55 to 60 years due to the low incidence of malignancy detected with the age $>55$ cut-off. The South African guidelines published in 1999 suggest that dyspepsia patients $\geq 45$ years undergo routine endoscopic evaluation. ${ }^{3}$ The evaluation of age as a risk factor for significant endoscopic findings in the context of dyspepsia is controversial.

The aim of this study was to provide an analysis of patients with dyspepsia only symptoms, who underwent an endoscopy in a South African hospital and to compare age above and below 60 as a predictor of significant endoscopic findings. A comparison was made with the local South African guidelines in an attempt to identify an appropriate age cut-off for screening endoscopy.

\section{Methods}

The study was conducted at Madadeni Provincial Hospital - a regional referral hospital in northern KwaZulu-Natal Province.

A retrospective chart review of 1000 consecutive endoscopies was performed for the period January 2014 to December 2016. Data were extracted from the endoscopy report book and entered into a Microsoft Excel spreadsheet. All patients $\geq 13$ years were included in the study. Incomplete patient records and abandoned procedures were excluded from the data analysis. Demographic data (age and gender) and indication for endoscopy (dyspepsia, upper gastrointestinal bleeding, reflux, anaemia, weight 
loss, dysphagia and corrosive ingestion) were recorded. Post-endoscopic findings (gastritis, normal, candidiasis, oesophagitis, stricture, gastric tumour, oesophageal tumour, hiatus hernia, peptic ulcer disease, oesophageal varices) were recorded.

A subgroup of patients with dyspepsia only symptoms were identified and divided into four cohorts (age $<60$ and age $\geq 60$ and age $<45$ and age $\geq 45$ ). Demographic data and post-endoscopic findings were analysed in both groups. Significant endoscopic findings were defined as the macroscopic presence of a stricture, ulcer or tumour. Nonsignificant findings were defined as the macroscopic presence of gastritis, normal, hiatus hernia, candida, and oesophagitis. The definitions of significant and non-significant endoscopic findings were based on a study by Wallace et al. that used the above descriptions to classify endoscopic findings when evaluating dyspepsia patients. ${ }^{4}$

Statistical analysis was performed using the Statistical Package for Social Sciences (SPSS) version 25.0 (IBM Corporation, New York). The overall characteristics of the study population were summarised using descriptive statistics, which included frequencies (\%) for categorical variables or median (interquartile range) for continuous variables. The chi-squared test was used to compare categorical variables. A $p$-value of $<0.05$ was considered statistically significant. As the existing South African guidelines (SAGES) are over ten years old, it was also decided that the age $\geq 45$ years threshold be re-evaluated in our study population using receiver-operator characteristic (ROC) curve analyses. The ROC curve and the Youden index was used to find the optimal age threshold for significant endoscopic findings in our study population. Standard 2 × 2 epidemiological tables were used to determine the accuracy of the various age thresholds for the detection of significant endoscopic findings in our setting. Measures of accuracy included sensitivity $(\%)$, specificity $(\%)$, odds ratios (OR with $95 \%$ confidence intervals - CI), positive predictive value (PPV, \%), and negative predictive value (NPV, \%).

\section{Results}

Of the 1000 endoscopies analysed, the indications included: dyspepsia only $n=584(58.4 \%)$; upper gastro-intestinal haemorrhage $n=166$ (16.6\%); dysphagia $n=102(10.2 \%)$; gastro-oesophageal reflux $n=76(7.6 \%)$; anaemia $n=39$ (3.9\%); corrosive ingestion $n=26(2.6 \%)$; foreign body $n=4(0.4 \%)$ and weight loss $n=3(0.3 \%)$. Dyspepsia patients $(n=584)$ were selected from the database and further analysed. The median age of the entire dyspepsia cohort was 49 years (range: 14-87). There were 142 males (24.4\%) and 442 females $(75.6 \%)$. The post-endoscopic findings were divided into significant and non-significant for the entire dyspepsia cohort (Table 1). Most dyspeptic patients had non-significant endoscopic findings (90.5\%) and significant findings were seen in only $9.5 \%$ of cases. The overall prevalence of malignancy was $n=9(1.5 \%)$. The overall prevalence of functional dyspepsia, as defined by dyspepsia with normal endoscopic findings, was $n=161$ $(27.5 \%){ }^{1}$

There were $432(74 \%)$ patients in the age $<60$ cohort and $152(26 \%)$ in the age $\geq 60$ cohort. In the age $<60$ cohort, $6.7 \%(29 / 432)$ had significant findings compared to $17.1 \%$ $(26 / 152)$ of patients in the age $\geq 60$ cohort $(p<0.001)$.

There were $238(41 \%)$ patients in the $<45$ cohort and 346 $(59 \%)$ patients in the $\geq 45$ cohort. In the age $<45$ cohort, $4.2 \%(10 / 238)$ had significant findings compared to $13 \%$ $(45 / 346)$ of patients in the age $\geq 45$ cohort $(p<0.001)$. There is no overall difference in significant endoscopic findings between the age $\geq 45$ and age $\geq 60$ groups ( $p=0.230$, calculated using Z-test for proportions).

The post-endoscopic findings in the age $<60$ and age $\geq 60$ cohorts are listed in Table 1.

Table 1: Demographic data and post-endoscopic findings for dyspepsia patients in the age $\geq 60$ and age $<60$ cohorts

\begin{tabular}{|c|c|c|c|c|c|c|c|}
\hline Age $\geq 60$ & $n=152$ & $\%$ & Age $<60$ & $n=432$ & $\%$ & Total cohort $n=584$ & $\%$ \\
\hline Age & 67 & & Age & 42 & & 49 & \\
\hline Min & 60 & & Min & 14 & & 14 & \\
\hline Max & 87 & & Max & 59 & & 87 & \\
\hline Males & 30 & 19.7 & Males & 112 & 25.9 & 142 & 75.6 \\
\hline Females & 122 & 80.2 & Females & 320 & 74.1 & 442 & 24.4 \\
\hline Non-significant findings & & & Non-significant findings & & & Non-significant findings & \\
\hline Gastritis & 82 & 53.9 & Gastritis & 217 & 50 & 299 & 51.1 \\
\hline Oesophagitis & 4 & 0.9 & Oesophagitis & 13 & 3 & 17 & 2.9 \\
\hline Candida & 7 & 1.62 & Candida & 31 & 7 & 38 & 6.5 \\
\hline Hiatus hernia & 7 & 1.62 & Hiatus hernia & 7 & 1.6 & 14 & 2 \\
\hline Normal & 26 & 17.1 & Normal & 135 & 31 & 161 & 27.5 \\
\hline Total & $126 / 152$ & 82.9 & Total & $403 / 432$ & 93.2 & $529 / 584$ & 90.5 \\
\hline Significant findings & & & Significant findings & & & Significant findings & \\
\hline Gastric tumour & 4 & 0.9 & Gastric tumour & 3 & 0.7 & 7 & 1.1 \\
\hline $\begin{array}{l}\text { Benign oesophageal } \\
\text { stricture }\end{array}$ & 0 & 0 & $\begin{array}{l}\text { Benign oesophageal } \\
\text { stricture }\end{array}$ & 0 & 0 & 0 & 0 \\
\hline Oesophageal cancer & 2 & 1.3 & Oesophageal cancer & 0 & 0 & 2 & 0.3 \\
\hline Benign peptic ulcer & 20 & 13.1 & Benign peptic ulcer & 26 & 6 & 46 & 7.9 \\
\hline Total & $26 / 152$ & 17.1 & Total & $29 / 432$ & 6.7 & $55 / 584$ & 9.4 \\
\hline
\end{tabular}


Table 2: 2 × 2 tables comparing significant and non-significant endoscopic findings in dyspeptic patients $<60$ and $\geq 60$ years old and in $<45$ and $\geq 45$ years old $*$

\begin{tabular}{cccccccc}
\hline & $\begin{array}{c}\text { Significant } \\
\text { endoscopic findings }\end{array}$ & $\begin{array}{c}\text { Non-significant } \\
\text { endoscopic findings }\end{array}$ & Total & & $\begin{array}{c}\text { Significant } \\
\text { endoscopic findings }\end{array}$ & $\begin{array}{c}\text { Non-significant } \\
\text { endoscopic findings }\end{array}$ & $\begin{array}{c}\text { Total } \\
\text { Age }<60\end{array}$ \\
29 & 403 & 432 & Age $<45$ & 10 & 228 & 238 \\
Age $\geq 60$ & 26 & 126 & 152 & Age $\geq 45$ & 45 & 301 & 346 \\
& 55 & 529 & 584 & & 55 & 529 & 584
\end{tabular}

* p-value $<0.001$ for all age cut-offs investigated

Table 3: Analysis of different age cut-offs $(\geq 45$ and $\geq 60$ ) with sensitivity, specificity, positive predictive value, negative predictive value and odds ratios*

\begin{tabular}{cccccc}
\hline Age cut-offs & OR (95\% CI) & Sensitivity (95\% CI) & Specificity (95\% CI) & PPV (95\% CI) & NPV (95\% CI) \\
\hline$\geq 45$ & $3.41(1.68-6.91)$ & $82(69-91 \%)$ & $43(39-47 \%)$ & $13(10-17 \%)$ & $96(92-98 \%)$ \\
$\geq 60$ & $2.87(1.63-5.05)$ & $47(34-61 \%)$ & $76(34-61 \%)$ & $17(11-24 \%)$ & $93(91-95 \%)$
\end{tabular}

*p value $<0.001$ for both age cut-offs

$\mathrm{PPV}$ - positive predictive value, NPV - negative predictive value, $\mathrm{OR}$ - odds ratios

There was a significantly higher percentage of functional dyspepsia in the $<60$ age group than in the $\geq 60$ age group (31\% vs 17.1\%) (OR: 2.2028, CI 0.95: 1.3786-3.5197; $p=0.001)$.

Dyspepsia patients $\geq 60$ years had a significantly higher rate of significant endoscopic findings than patients $<60$ years (OR: 2.87, 95\% CI: 1.63-5.05; $p<0.001$ ). Dyspepsia patient $\geq 45$ years also had a significantly higher rate of significant endoscopic findings than patients $<45$ years. (OR: 3.41, 95\% CI: 1.68-6.91; $p<0.001$ ) (Table 2).

The odds of a significant endoscopic finding in the $\geq 45$ age group was 3.41 and 2.87 in the $\geq 60$ age group. This supports our hypothesis that age is a predictor of significant endoscopic findings in dyspepsia patients. Overall, this translates to an approximate 3 -fold higher odds significant endoscopic findings in both the age $\geq 45$ and age $\geq 60$ cohorts. As shown in Table 3, the PPV in the age $\geq 45$-year cohort $(13 \%)$ and age $\geq 60$ cohort $(17 \%)$ was low whereas the NPV in the age $\geq 45$ cohort and age $\geq 60$ cohort were comparably high ( $96 \%$ and $93 \%$, respectively). The optimal cut-off age in our study population determined from the ROC curve analysis was 47 years. Using this age threshold, the sensitivity was $79 \%$, specificity $49 \%$, NPV $95 \%$, and PPV 13\%. The CIs for the accuracy measures for the age $\geq 47$ cohort were found to overlap with the CIs for age $\geq 45$ and age $\geq 60$ thresholds and were therefore considered to be statistically similar (i.e. $p>0.05$ ).

\section{Discussion}

In this study, dyspepsia was the commonest indication for endoscopy, with an overall hospital prevalence of $58.4 \%$. Although the exact prevalence in South Africa is unknown, the percentage in this study is higher than in previous African studies, which showed a prevalence of $26 \%{ }^{2}$ A more recent study from Nigeria showed a prevalence of $68.6 \%$ during 2005-2010, which is more comparable with our results. ${ }^{5}$ Nwokediuko et al. showed a $69.1 \%$ prevalence of dyspepsia in patients undergoing endoscopy for upper gastrointestinal symptoms, while Ijarotimi et al. showed that $74.6 \%$ of patients underwent endoscopy for dyspepsia. ${ }^{5,6}$ An increasing prevalence of dyspepsia has been noted in the last two decades. Female dyspeptic patients account for most patients undergoing endoscopic evaluation (75.6\%). A large meta-analysis by Ford et al. showed a higher pooled prevalence of dyspepsia in women compared with men ( 25.3 vs $21.9 \%$ ), which still remains much lower than the prevalence seen in our study $(75.6 \%)$ prevalence. ${ }^{7} \mathrm{~A}$ systematic review on gender-based prevalence studies has shown that the prevalence of dyspepsia in men and women is inconsistent. ${ }^{8}$ We postulate that women are more likely to seek healthcare for dyspepsia symptoms than men and this accounts for the higher number of endoscopies being performed in females. ${ }^{9}$

In this study, the overall prevalence of functional dyspepsia was $27.5 \%$. which is in contrast to a recent Nigerian study that showed the prevalence of functional dyspepsia was $64.9 \% .{ }^{6}$ We postulate that the high percentage of functional dyspepsia can be attributed to the widespread availability and use of proton pump inhibitors at primary healthcare level. Patients are often treated and then referred for endoscopic evaluation after therapy has commenced, resulting in normal endoscopic findings. Our study found that functional dyspepsia is significantly more common in the $<60$ age group $(31 \%)$ than in the $>60$ age group (17.1\%). Our findings support several studies that have shown a decreasing trend of functional dyspepsia with age; however, functional dyspepsia is not confined to any particular age group. ${ }^{10-12}$

The high prevalence of dyspepsia poses a diagnostic challenge to facilities where endoscopy services are limited by the lack of equipment and trained endoscopists. A recent audit of endoscopy services in KwaZulu-Natal showed that endoscopy units are not adequately equipped to deal with the endoscopy workload and are frequently plagued with disruptions due to equipment failure. ${ }^{13}$ Internationally accepted guidelines are necessary to ensure that endoscopy is done for the correct indication, and to avoid medico-legal litigation. These guidelines are often formulated in high- to middle-income countries, however, and their implementation in the South African context has not been validated.

Age is a defining feature of the ACG guidelines on dyspepsia, and directs the initial investigative workup of dyspepsia patients. ${ }^{1}$ The ACG guidelines recommend 60 years as the age above which they recommend routine endoscopy. Below 60 years a Helicobacter pylori (H. pylori) 'test and treat' strategy for dyspepsia patients forms a major diagnostic and therapeutic arm in the management of dyspepsia patients. The 'test and treat' 
strategy has been shown to be a safe method for managing uninvestigated dyspepsia in patients up to the age of 60 years. ${ }^{14}$ The public hospitals in KwaZulu-Natal are not employing a 'test and treat' strategy when treating dyspepsia patients due to a lack of stool antigen test kits, radioisotope compounds, scintillation counters and skilled personnel. This lack of a non-invasive alternative to endoscopy for the diagnosis of $H$. pylori drives the need to endoscope young patients with dyspepsia. The rationale for screening dyspepsia patients aged $\geq 60$ is based on the perceived risk of gastric malignancy being higher in this age group. Endoscopy can detect gastric malignancy at an early stage. ${ }^{15}$ In the age group $<60$, the risk of gastric malignancy is $<1 \%$. ${ }^{1}$ Our study has shown the rate of gastric tumours to be $1.1 \%$ in dyspepsia patients, which concurs with international trends.

The justification for a specific age cut-off has variable support in the literature. Wallace et al. have shown that age was a poor predictor of major endoscopic findings (ulcer, stricture and tumour), and recommended that better clinical protocols be established. ${ }^{4}$ In their study, significant endoscopic findings increased in a linear fashion from age 45 to 65 , however the sensitivity was $85 \%$ and the specificity was only $26 \%$. A recent study by Abdeljawad et al. has shown that dyspeptic patients have a low prevalence of significant endoscopic findings and age $\geq 55$ is associated with higher risk of significant endoscopic findings. ${ }^{16}$ The prevalence of a significant endoscopic finding was 10.2\% with a prevalence of malignancy of $0.8 \%$. Our study has shown similar results with only $9.7 \%$ of dyspepsia patients having a significant endoscopic finding with an overall low prevalence of malignancy of $1.5 \%$.

We report high negative predictive values for significant endoscopic findings when the age $\geq 45$ and age $\geq 60$ are used. Despite 47 years old being identified as the optimal age threshold in our study population, the measures of accuracy for this age cut-off were not found to be statistically different from those obtained for the age $\geq 45$ and age $\geq 60$ thresholds. The PPV for screening patients age $\geq 45$ years is low (13\%) whilst the NPV for the age $\geq 60$ cut-off is $93 \%$, which implies that patients with dyspepsia under age 60 will have a $93 \%$ probability of having a non-significant finding at endoscopy. We recommend that a revision to the 1999 SAGES guidelines be considered, due to the comparable diagnostic yields of endoscopy performed in the $\geq 45$ year and $\geq 60$-year groups in our study. Adoption of the ACG guidelines would reduce the number of unnecessary endoscopies performed on dyspepsia patients and also reduce the burden on endoscopy services in under-resourced areas, such as our study setting.

There are several limitations to this study. As it is retrospective in design, we had to rely on patients' records from an endoscopy report book, which is subject to clinician and observer error. Patients whose records were analysed may not be representative of the general population, as this was a regional, hospital-based study in a rural area.

\section{Conclusion}

Age is a strong predictor of significant endoscopic findings in dyspepsia patients, which still remains the commonest indication for upper gastrointestinal endoscopy. The current ACG guidelines recommending that dyspepsia patients $\geq 60$ years undergo endoscopy are appropriate in the South
African context. Consideration should be given to accruing more national data with a view to revising the 1999 SAGES dyspepsia guidelines regarding the age cut-off and in respect to recommendation's regarding $H$. pylori 'test and treat' strategy.

\section{Conflict of interest}

The authors have no conflict of interest to declare.

\section{Funding source}

The study did not require any funding.

\section{Ethics approval}

The author/s declare that this submission is in accordance with the principles laid down by the Responsible Research Publication Position Statements as developed at the $2^{\text {nd }}$ World Conference on Research Integrity in Singapore, 2010.

Ethical approval to conduct the study was granted by the Biomedical Research Ethics Committee of University of KwaZulu-Natal (BREC 620/17).

\section{ORCID}

S Cheddie (iD http://orcid.org/0000-0002-1844-5759

CG Manneh (iD http:/orcid.org/0000-0001-9761-0603

BM Owczarek (iD http://orcid.org/0000-0002-0069-5759

Y Moodley (iD) http://orcid.org/0000-0002-4119-1734

\section{REFERENCES}

1. Moayyedi PM, Lacy BE, Andrews CN, et al. ACG and CAG clinical guideline: Management of dyspepsia. Am J Gastroenterol. 2017 Jul;112(7):988-1013. http://doi. org/10.1038/ajg.2017.154.

2. Holcombe C, Omotara BA, Padonu MK, Bassi AP. The prevalence of symptoms of dyspepsia in north eastern Nigeria. A random community-based survey. Trop Geogr Med. 1991;43(1-2):209-14.

3. Louw JA, Pinkney-Atkinson V. Diagnosis and management of dyspepsia - clinical guideline, 1999. Dyspepsia Working Group, South African Medical Association, South African Gastroenterology Society Working Group. SAMJ. 1999 Aug;89(8 Pt 2):897-903.

4. Wallace MB, Durkalski VL, Vaughan J, et al. Age and alarm symptoms do not predict endoscopic findings among patients with dyspepsia: A multicentre database study. Gut 2001;49:2934. https://doi.org/10.1136/gut.49.1.29.

5. Ijarotimi O, Soyoyo DO, Adenkanle O, et al. Declining prevalence of duodenal ulcer at endoscopy in Ile-Ife, Nigeria. S Afr Med J. 2017;107(9):750-3. http://doi.org/10.7196/ SAMJ.2017.V107i9.12342.

6. Nwokediuko SC, Ijoma U, Obienu O. Functional dyspepsia: Subtypes, risk factors, and overlap with irritable bowel syndrome in a population of African patients. Gastroenterol Res Pract. 2012;2012:562393[5 p.]. Epub 2012 Nov 19. https://doi.org/10.1155/2012/562393.

7. Ford AC, Marwaha A, Sood R, et al. Global prevalence of, and risk factors for, uninvestigated dyspepsia: A metaanalysis. Gut. 2015;64(7):1049-57. https://doi.org/10.1136/ gutjnl-2014-307843.

8. Ahlawat SK, Cuddihy MT, Locke GR 3rd. Gender-related differences in dyspepsia: A qualitative systematic review. Gend Med. 2006;3(1):31-42. https://doi.org/10.1016/s15508579(06)80192-0. 
9. Koloski NA, Talley NJ, Boyce PM. Epidemiology and health care seeking in the functional GI disorders: A populationbased study. Am J Gastroenterol. 2002;97(9):2290-9. https:// doi.org/10.1016/s0002-9270(02)04139-4.

10. Kay L, Jorgensen T. Epidemiology of upper dyspepsia in a random population. Prevalence, incidence, natural history, and risk factors. Scand J Gastroenterol. 1994;29:2-6. https:// doi.org/10.3109/00365529409090.

11. Caballero-Plasencia AM, Sofos-Kontoyannis S, ValenzuelaBarranco M, et al. Irritable bowel syndrome in patients with dyspepsia: A community-based study in southern Europe. Eur J Gastroenterol Hepatol. 1999;11:517-22. https://doi. org/10.1097/00042737-199905000-00009.

12. Shaib Y, El-Serag HB. The prevalence and risk factors of functional dyspepsia in a multiethnic population in the United States. Am J Gastroenterol. 2004;99:2210-6. https://doi. org/10.1111/j.1572-0241.2004.40052.x.

13. Loots E, Clarke DL, Newton K, et al. Endoscopy services in KwaZulu-Natal Province, South Africa, are insufficient for the burden of disease: Is patient care compromised? S Afr Med J. 2017;107(11):1022-5. https://doi.org/10.7196/SAMJ.2017. v107i11.12484.

14. Farkkila M, Sarna S, Valtonen V, et al. Does the 'test-andtreat' strategy work in primary health care for management of uninvestigated dyspepsia? A prospective two-year follow-up study of 1552 patients. Scand J Gastroenterol. 2004;39:32735. https://doi.org/10.1080/00365520310008674.

15. Spahos T, Hindermarsh A, Cameron E, et al. Endoscopy waiting times and impact of the two-week wait scheme on diagnosis and outcome of upper gastrointestinal cancer. Postgrad Med J. 2005;81:728-30. https://doi.org/10.1136/ pgmj.2004.031104.

16. Abdeljawad K, Wehbeh A, Quayed E. Low prevalence of clinically significant endoscopic findings in outpatients with dyspepsia. Gastroenterol Res Pract. 2017;3543681[7 p.]. Epub 2017 Jan 22. https://doi.org/10.1155/2017/3543681. 